\title{
PEMBINAAN WIRAUSAHA MAHASISWA MELALUI PRODUKSI TARI DAN PERMAINAN ANAK-ANAK
}

\author{
Juju Masunah, Putri Lilis Dyani, Ayo Sunaryo, Tati Narawati, Trianti \\ Nugraheni, dan Yoyoh Siti Mariah
}

\author{
Departmen Pendidikan Tari, Fakultas Pendidikan Seni dan Desain (FPSD), Universitas \\ Pendidikan Indonesia, Jl. Setiabudi 229 Bandung 40154 \\ Email: jmasunah@upi.edu
}

\begin{abstract}
ABSTRAK
Peningkatan jumlah mahasiswa wirausaha merupakan salah satu indikator capaian Renstra Universitas Pendidikan Indonesia (UPI), maka kelompok tim dosen Departemen Pendidikan Tari, Fakultas Pendidikan Seni dan Desain (FPSD) membina 34 mahasiswa melalui program Pengabdian kepada Masyarakat tentang kewirausahaan seni. Tujuan Pengabdian kepada Masyarakat $(\mathrm{PkM})$ ini adalah untuk membina wirausaha mahasiswa melalui produksi seni tari dan permainan anak-anak. Metode yang digunakan dalam PkM ini adalah project based approach, yaitu sebuah pendekatan berbasis projek. Karakteristik pendekatan ini yaitu keterlibatan peneliti sangat besar dalam membantu subjek untuk mewujudkan sebuah projek. Kegiatannya diawali oleh: 1) mendiagnosa permasalahan mahasiswa dalam wirausaha seni; 2) merumuskan rancangan pemecahan masalah; 3) mengimplementasikan rancangan wirausaha melalui produksi tari dan permainan anak; 4) evaluasi berupa presentasi produk melalui pertunjukan virtual. Melalui PkM ini dihasilkan lima kelompok mahasiswa wirausaha, dua kelompok yang memproduksi tari anak dan satu kelompok memproduksi permainan anak, satu kelompok memproduksi model pembelajaran, dan satu kelompok memproduksi promosi tari anak. Respon pasar yang disampaikan melalui google form sebanyak 109 penonton yang mengakses tayangan virtual melalui TV UPI Digital, menggambarkan $>70 \%$ yang menyatakan sangat bagus produk seninya, dan $>90 \%$ ingin belajar dan ingin menonton kembali. Hal ini menunjukkan bahwa wirausaha mahasiswa dengan produksi tari dan permainan anak diminati oleh apresiatornya. Produk tari dan permainan anak menawarkan jasa pertunjukan tari dan jasa pelatih tari bagi anak dan guru sekolah.

Kata Kunci: Mahasiswa, Pendidikan Tari, Permainan Anak-anak, Tari Anak, Wirausaha
\end{abstract}




\begin{abstract}
Increasing quantity of students' entrepreneur is one of achievement indicators in Universitas Pendidikan Indonesia (UPI)'s Strategy Plan, therefore the faculty members from Department of Dance Education, Faculty of Arts and Design Education UPI mentored 34 students in the community service program to develop entrepreneurship activities in the field of arts. The purpose of community service activities is to mentor students' entrepreneurships based on the production of children dance and traditional games. The method for the community service program used a project-based approach. The characteristic of this method is the researchers actively participate in helping the participants to build the project. The activity began with: 1) diagnosing the students' problems to build entrepreneurial arts; 2) by developing business plan to solve the problems based on the production of children dance and the traditional games; 3) implementing the business plan; 4) an evaluation by presenting the product through virtual arts event. Through the community service program, five groups of students produced two children dances and the traditional games, arts teaching and learning, and the promotion of events. The researches asked appreciators to give a response of the event through filling a google form. There are 109 audiences who access the event virtually through TV UPI Digital and fill in the form. More than $>70 \%$ stated the production is very good and more than $>90 \%$ appreciators want to watch the virtual event again. The findings inform that the students succeed to attract people with children' dances and the traditional games. Through this project, the students offered the product of performing arts and a service for trainers about teaching children's dance and the traditional games.
\end{abstract}

Keywords: children dance, dance education, student entrepreneur, traditional games

\section{PENDAHULUAN}

Wirausaha mahasiswa saat ini sedang digalakkan melalui berbagai program, antara lain Program Kreativitas Mahasiswa (PkM), baik dari Pemerintah Pusat, Pemerintah Daerah, maupun universitas. Sumarsono (2013), melaporkan bahwa Badan Resmi Statistik pada tahun 2010 mencatat pengangguran kalangan terdidik tingkat diploma dan sarjana meningkat 2,05 persen dan 1,16 persen. Karyaningsih (2017), melaporkan bahwa pada tahun 2016 angka pengangguran di Indonesia mencapai 7,02 juta jiwa atau 5,5 persen. Kebijakan Universitas Pendidikan Indonesia yang tertuang dalam Renstra UPI 2016-2020 mencantumkan pengembangan kewirausahaan mahasiswa. Dalam kurikulum UPI, di setiap fakultas memiliki mata kuliah kewirausahaan sebagai mata kuliah wajib fakultas. Program maupun mata kuliah kewirausahaan di Perguruan Tinggi tampaknya salah satu upaya untuk mengurangi pengangguran. Lulusan Perguruan Tinggi diharapkan menjadi job creator (pencipta lapangan kerja) daripada job seeker (pencari kerja). Latar belakang inilah, kami membina kelompok mahasiswa untuk berwirausaha dalam bidang seni dan pembelajarannya. Mahasiswa yang menjadi sasaran $\mathrm{PkM}$ ini adalah mahasiswa S1 dan alumni UPI, khususnya Departemen Pendidikan Tari Fakultas Pendidikan Seni dan 
desain (FPSD) dan mahasiswa S1 Fakultas Pendidikan Ekonomi Bisnis (FPEB).

Seni merupakan bagian dari sub sector industri kreatif di Indonesia. Kementrian Pariwisata dan Ekonomi Kreatif dan Badan Statistik Nasional (Pangestu, 2014) telah membuat Klasifikasi Baku Lapangan Usaha Indonesia (KBLI) Bidang Ekonomi Kreatif untuk 15 subsektor yaitu: arsitektur, desain, film-videofotografi, kuliner, kerajinan, mode (fashion), musik, penerbitan, permainan interaktif, penelitian dan pengembangan, seni pertunjukan, teknologi informasi, televisi dan radio. Khususnya subsektor seni pertunjukan, lapangan usaha masih terbatas, meskipun keterserapan tenaga kerja subsektor seni pertunjukan dan industri musik secara nasional cukup besar (Pangestu, 2014).

Dalam konsep industri kreatif, terdapat rantai nilai yang diawali dari kreasi, produksi, promosi, distribusi untuk mencapai target pasar, sehingga pelaku kreatif memperoleh nilai tambah secara sosial, budaya, dan ekonomi (Masunah, 2019b). Pembinaan wirausaha mahasiswa memiliki target pasar yaitu anakanak, orangtua, dan guru sekolah. Target pasar ini untuk tujuan pendidikan anak melalui seni. Selain itu, kampus UPI sudah dijadikan salah satu destinasi wisata Kota Bandung sejak tahun 2016. Hampir setiap hari Bandung on the Bus (Bandros) membawa anak-anak dan keluarga untuk mengunjungi UPI, tetapi atraksi seni pertunjukan sebagai cultural event harian atau mingguan untuk anak-anak belum ada. Hal ini merupakan peluang bagi Fakultas Pendidikan Seni dan Desain untuk membuat atraksi seni yang dapat dijadikan event rutin sebagai sebuah bentuk atraksi tari dan permainan untuk anak-anak dan keluarga. Kegiatan $\mathrm{PkM}$ terdahulu pada tahun 2019 melaporkan bahwa melalui sebuah projek produksi wayang kontemporer untuk pendidikan dan dipasarkan kepada anak dan keluarga, telah mampu menumbuhkan motivasi kewirausahaan mahasiswa untuk membuat paket kunjungan ke UPI dengan menambah penjualan barangbarang seni dan atraksi seni lainnya (Masunah, 2019a).

Tujuan pembinaan wirausaha mahasiswa melalui produksi tari dan permainan anak-anak adalah untuk menumbuhkan jiwa kewirausahaan dengan pengalaman dalam bidang industri kreatif sub sektor seni pertunjukan. Sudah sejak lama program-program bidang seni di UPI digagas untuk tontonan turis atau wisatawan, namun sasaran pasar secara spesifik belum dipetakan. Permasalahannya adalah bagaimana membina kelompok-kelompok mahasiswa ini agar produksi seninya dapat dinikmati anak-anak dan bermakna bagi pendidikan anak?

Maka, PkM kewirausahaan ini difokuskan untuk membina sejumlah mahasiswa Departemen Pendidikan Tari dan mahasiswa bidang manajmen serta pariwisata untuk berkolaborasi dalam mewujudkan wirausaha berbasis tari dan permainan untuk anak-anak. Produk ini merupakan sebuah bentuk pendidikan informal yang menarik dan atraktif sekaligus berperan 
rekreasi dan edukasi. Tim Dosen UPI mendampingi mahasiswa dalam kegiatan:

1) memproduksi karya tari untuk target pasar anak-anak dan keluarga;

2) mengembangkan pembelajaran tari bagi anak-anak secara virtual;

3) mempromosikan karya tari tersebut ke sekolah-sekolah dan melalui media sosial;

4) memasarkan produksi tari anak dan permainan anak-anak serta pembelajarannya.

\section{METODE}

Metode yang digunakan dalam membina kelompok wirausaha mahasiswa adalah project based approach. Stoecker (2005), dalam bukunya Research Methods for Community Change menawarkan sebuah pendekatan berbasis projek atau a project-based approach untuk melakukan perubahan pada masyarakat. Stoecker (2005), memberi langkah-langkah untuk melakukan pendekatan ini yang dimulai dari mendiagnosa masalah, membuat resep atau rancangan solusinya, mengimplementasikan, dan mengevaluasi. Pemikiran Stoecker ini akan dirujuk dalam mengembangkan wirausaha seni sebagai sebuah solusi untuk membangun kelompok wirausaha seni pertunjukan di UPI.

Kalayak sasaran kegiatan PkM ini adalah mahasiswa aktif S1 dan alumni yang berlatar belakang Pendidikan seni tari serta mahasiswa berlatar belakang bidang manajmen dan pariwisata. Kolaborasi mahasiswa lintas bidang ilmu digagas oleh Pusat Penelitian dan
Pengembangan Ekonomi Kreatif,

Kewirausahaan, dan Industri Pariwisata (selanjutnya disingkat Pusat Penelitian EKKIP) Lembaga Penelitian dan Pengabdian Kepada Masyarakat (LPPM) UPI. Lokasi kegiatan bertempat di Universitas Pendidikan Indonesia, Bumi Siliwangi, Jl. Setiabudi 229 Bandung 40154. Kegiatan PkM ini dilaksanakan pada masa pandemic Covid-19 yaitu pada bulan Agustus sampai dengan Oktober 2020. Maka dari itu, terdapat langkah-langkah kegiatan yang memperhatikan protokol kesehatan, antara lain kegiatan yang dilakukan melalui jarak jauh dengan perantara jaringan teknologi, untuk berkoordinasi dengan mahasiswa dan dosen lainnya, proses produksi, promosi serta pemasaran produk seni dilakukan secara virtual.

Kegiatan diawali dengan mendiagnosa mahasiswa. Kegiatan awal ini dilakukan pada bulan September 2020. Tim peneliti menyiapkan pendaftaran untuk kegiatan workshop terkait dengan kewirausahaan yang diselenggarakan oleh Pusat Penelitian EKKIP LPPM UPI. Dalam pendaftaran ini terdapat 50 orang mahasiswa yang berasal dari Pendidikan Tari FPSD UPI dan 50 orang dari Prodi Manajemen dan Pendidikan Pariwisata Fakultas Pendidikan Ekonomi dan Bisnis (FPEB). Dalam kegiatan workshop, para Pembina atau Tim PkM menawarkan kegiatan produksi tari dan permainan anak-anak serta pembelajarannya sebagai sebuah produk dalam berwirausaha, serta satu kelompok promosi seni. Berdasarkan minat mahasiswa terdiagnonasa 3 kelompok yaitu 2 
kelompok yang akan memproduksi Tari Anak dan satu kelompok yang akan memproduksi permainan anak. Agar kelompok ini fokus pada produksi tari, maka Pusat Penelitian EKKIP LPPM UPI membentuk kelompok guru atau instruktur yang akan mengajarkan karya seni kepada siswa, serta kelompok yang berperan mempromosikan produk tersebut. Hal ini mempertimbangkan bahwa kelompok wirausaha pemula dan dalam waktu yang pendek, mahasiswa dari bidang pendidikan tari hanya akan mampu memproduksi karya tari anak dan permainan anak, sedangkan pembelajaran, promosi dan pemasarannya masih merasa kesulitan.

Langkah kedua adalah membuat rancangan. Rancangan ini merupakan solusi atas masalah yang dihadapi mahasiswa dalam wirausaha. Untuk memproduksi karya tari anak dan permainan anak didampingi oleh seorang dosen yang ahli dalam bidangnya. Dua kelompok lain yaitu kelompok instruktur dan kelompok promosi seni wisata, juga didampingi oleh dosen. Setiap kelompok berjumlah 6 dan 7 orang mahasiswa. Projek dirancang mulai dari produksi karya tari dengan bahan permainan anak-anak dan tema yang berorientasi pada pendidikan karakter anak.

$$
\text { Langkah ketiga adalah }
$$
mengimplementasikan rancangan projek. Produksi karya tari anak dan permainan anak dilakukan pada bulan September dan Oktober 2020. Pertemuan awal dilakukan secara daring untuk mendiskusikan konsep garap dan kegiatan latihan. Kegiatan latihan dilaksanakan pada bulan
Oktober secara tatap muka dengan masing-masing dosen pendamping. Setiap kelompok menempati lokasi latihan di ruang terbuka di kampus UPI Bumi Siliwangi. Ketika sudah terwujud produk karya tari, maka kelompok instruktur mengadakan kolaborasi dan berdiskusi dengan kelompok tari, untuk menganalisis ciri khas gerak tari yang diproduksi serta nilai-nilai yang terkandung didalamnya. Hasil analisis ini, kemudian dikembangkan sebagai materi pembelajaran secara virtual. Setiap tarian diajarkan oleh seorang instruktur. Selanjutnya, kelompok promosi seni wisata mengembangkan akun Instagram @tourismedupreneur_edu. Tourism edupreneur adalah sebuah program Pusat Penelitian EKKIP LPPM UPI untuk mengembangkan wisata pendidikan dan pendidikan wirausaha mahasiswa dan alumni UPI.

Langkah akhir penelitian ini adalah evaluasi projek, yang dilaksanakan dalam bentuk pertunjukan seni virtual. Karya tari dan proses pembelajarannya ditampilkan melalui TV UPI Digital pada tanggal 24 Oktober 2020. Untuk mengetahui response apresiator atau uji pasar, kami membuat format isian atau questioners melalui google form untuk menilai produk tari anak dan permainan anak. Questionnaires dibuat pilihan terdiri sangat baik, baik, biasa saja, dan jelek. Pertanyaan ini untuk menengetahui nilai secara kualitatif tentang produk karya tari. Kami juga menanyakan kepada penonton apakah "Anda ingin belajar dan ingin menonton lagi?". Pertanyaan tersebut disampaikan untuk memperoleh 
jawaban apakah projek ini mesti dilanjutkan atau tidak.

Empat tahapan dalam mewujudkan projek ini dilaksanakan untuk memperoleh gambaran tentang model pembinaan kelompok wirausaha mahasiswa dalam memproduksi seni, mempromosikan, dan memasarkannya. Kami mengobservasi secara partisipasi setiap tahap kegiatan untuk memperoleh gambaran semangat dan motivasi mahasiswa dalam berkarya. Kami juga melakukan perekaman produk karya dan kegiatannya dalam bentuk video dan foto. Dokumendokumen yang ada di dalam Instagram dikaji dari sisi konten kebahasaan untuk anak-anak dan teman mahasiswa. Data-data yang dikumpulkan kemudian dianalisis dan disajikan dalam laporan ini.

\section{HASIL DAN PEMBAHASAN}

\section{Memproduksi Karya Tari Anak dan Permainan Anak}

Dalam rangka memproduksi tari dan permainan anak, tim PkM melakukan tahapan kegiatan yang diawali dengan rekrutmen mahasiswa. Rekrutmen dilaksanakan pada bulan Agustus 2020 bersamaan dengan kegiatan pendaftaran workshop Ekonomi Kreatif dan Kewirausahaan yang dilaksanakan oleh Pusat Penelitian EKKIP LPPM UPI. Oleh karena, situasi pandemic covid-19, maka rekrutment mahasiswa dilakukan secara daring. Kami merekrut mahasiswa menggunakan registrasi google form (https:// bit.ly/3gRjLVR). Workshop juga dilaksanakan secara virtual pada tanggal 12 September 2020.
Mahasiswa dan alumni yang mengikuti kegiatan workshop berjumlah 197 orang. Sekitar 50 orang adalah mahasiswa S1 yang berasal dari Departemen Pendidikan Tari FPSD UPI, mahasiswa dari FPEB UPI, mahasiswa dari Padang serta beberapa alumni UPI. Dalam kegiatan workshop tersebut, tim PkM berperan sebagai narasumber yang memberi gambaran tentang tari anak dan permainan anak, serta pembelajaran tari bagi anak. Nara sumber dari luar UPI yang diundang oleh Pusat Penelitian EKKIP LPPM UPI menyajikan topik tentang ekonomi kreatif dan wirausahaan, lagu anak dan musik angklung, puppet untuk anak, bisnis startup, serta gambaran program Tourism Edupreneur yang dikembangkan oleh Pusat Penelitian EKKIP LPPM UPI.

Setelah kegiatan workshop, peserta, khususnya mahasiswa UPI diminta untuk membuat proposal pengembangan bisnis. Setiap kelompok mahasiswa, membuat rencana garapan dan rencana pendanaan untuk produksi karya, serta menetapkan target pasar yaitu anak-anak. Terdapat delapan kelompok yang mengajukan proposal bisnisnya, yaitu tiga kelompok mahasiswa yang membuat rancangan produksi seni yang bersumber dari permainan dan lagu anak, satu kelompok tentang pembelajaran tari secara virtual, satu kelompok tentang promosi seni untuk wisata, dua kelompok seni musik dan teater/puppet, serta satu kelompok penyelenggara festival.

Yang dilaporkan dalam tulisan ini, terbatas pada kegiatan yang berkaitan dengan Tari Anak dan 
Permainan Anak, pembelajaran tari anak, dan kelompok promosi seni. Alasannya adalah karya tersebut sarat dengan pesan-pesan, karakter kerjasama, kejujuran, yang mudah diserap anak-anak. Selain ini, memudahkan dalam menganalisis karya karena sesuai dengan bidang ilmu pengabdi.

Penggarap Tari Anak terdapat dua kelompok yaitu yang memproduksi karya berjudul "Sabilulungan" dan yang memproduksi karya "Kawanan Kelinci." Kelompok yang memproduksi karya permainan anak berjudul "Barudak di Buruan." Setiap kelompok didampingi oleh dosen pembimbing. Kemudian kelompok mahasiswa dan pembimbing mengimplementasikan rancangan produksi tari anak dan permainan anak. Tiga kelompok mahasiswa tersebut melakukan latihan secara daring dan luring dengan kurun waktu satu bulan (September-Oktober 2020). Setelah produk tari hampir selesai, satu kelompok mahasiswa mengembangkan pembelajaran tari secara virtual. Satu kelompok lagi berperan untuk mempromosikan seni yang dihasilkan oleh tiga kelompok penggarap tari. Kelima kelompok ini saling bekerjasama dengan tugas dan perannya masing-masing.

\subsection{Kelompok Tari "Sabilulungan"}

Sabilulungan berarti kerjasama. Kelompok ini dibentuk untuk menggarap tari yang membawa pesan karakter kerjasama. Kelompok Tari Anak "Sabilulungan" berjumlah 7 orang yang terdiri dari seorang ketua kelompok dan enam orang anggota. Ketua kelompok adalah Aditya Septian, S.Pd (alumni UPI) dan 6 orang anggotanya adalah mahasiswa baru Angkatan 2020 yaitu Diva Ramadhona Safitri; Esa Nurmaulida; Nadia Zahratunnisa A; Rangrang Dewi Kalista; Widi Eka Yulita; Yulia Dwiyanti. Mereka semua berperan sebagai penari. Pembimbing kelompok tari "Sabilulungan" adalah Dr. Ayo Sunaryo, M.Pd.

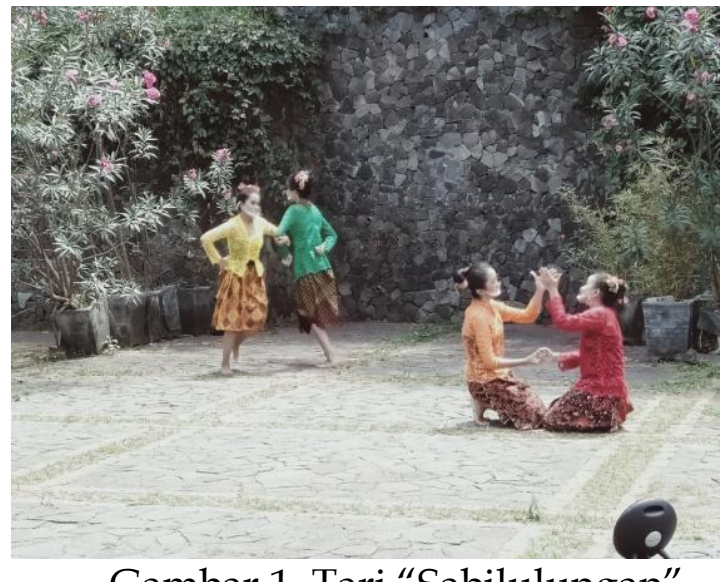

Gambar 1. Tari “Sabilulungan”

Dua pasang penari pada gambar 1 mengekspresikan Gerakan bermain dengan temannya. Tari "Sabilulungan" ini menceritakan eratnya tali persahabatan antara manusia dengan isi ekosistem di suatu hutan belantara. Ide ceritera ini merupakan garapan tari bertema. Pada suatu waktu datang seorang penjarah kayu hutan yang serakah. Penjarah kayu divisualkan sebagai bebegig, yaitu sosok hantu atau orang yang berfungsi untuk menakut-nakuti makhluk hidup lain. Bebegig mencerminkan sikap keserakahan orang yang tidak bertanggungjawab terhadap ekosistem hutan. Nur mana gadis yang tinggal di dalam hutan senantiasa merawat dan melestarikan ekosistem hutan di dalamnya. Hingga 
kemudian sampai saat keberanian Nur dengan teman-temannya bergotong royong mengusir bebegig tersebut. Dengan kekuatan persahabatan, mereka dapat mengusir bebegig tersebut keluar dari hutan.

$$
\text { Bebegig }
$$

(Gambar

divisualisasikan dengan topeng berwajah seperti hantu menakutkan yang ditarikan oleh Aditya Septian. Lima penari perempuan memakai kebaya dan kain menggambarkan anak-anak desa di daerah Sunda. Seorang anak laki-laki berpakaian hitam-hitam dan berikat kepala memerankan sebagai anak nakal yang sering mengganggu teman-teman perempuan. Gerakan tari yang dicipta untuk anak-anak perempuan menggunakan gerak sehari-hari seperti berjalan, melenggang sambil bernyanyi dengan iringan musik yang menggambarkan suasana pedesaan. Gerakan yang dilakukan secara berpasangan, dan gerakan yang dilakukan secara melingkar dengan cara berpegangan tangan.

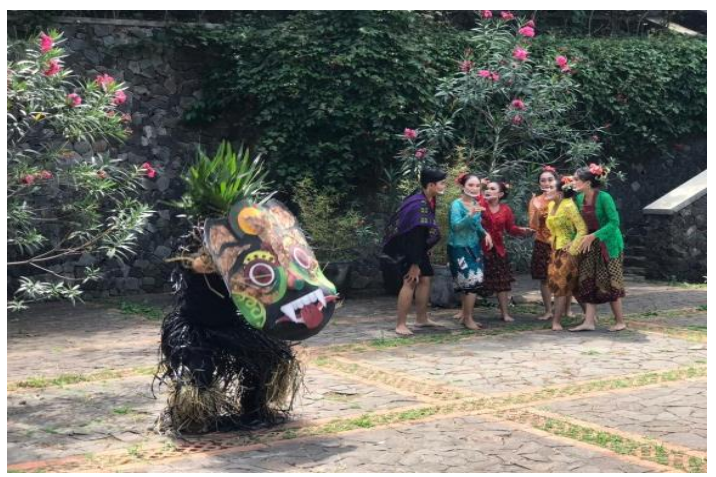

Gambar 2. Bebegig dan Penari "Sabilulungan"

Lokasi pentas menggunakan ruang terbuka Taman Baretti Villa Isola, dengan setting pentas Taman Botani Kampus UPI Bumi Siliwangi.

\subsection{Kelompok Tari Anak "Kawanan Kelinci"}

Tari Anak kedua berjudul "Kawanan kelinci." Kawanan berarti rombongan. Dibentuknya kelompok ini dengan tujuan untuk menggambarkan karakter kejujuran. Ketua kelompok Tari Kawanan Kelinci bernama Maulida Rahmani, S.Pd., seorang alumni Departemen Pendidikan Tari yang lulus tahun 2018. Ketua kelompok berperan sebagai koreografer dan tidak menari. Penari "Kawanan Kelinci" adalah anggota kelompok berjumlah enam orang yaitu Adisty Halimatus Solihah; Aqliyah Lutvy Triandini; Azahra Rifka Fairunisa; Dyinanti Fitrianiti; Fandan Nike Citra Auril; dan Nabila Intania Putri. Pembimbing tari anak "Kawanan Kelinci" adalah Dr. Ayo Sunaryo, M.Pd.

Tari "Kawanan Kelinci" ini menceritakan sekelompok kelinci yang sedang mencari makan di sebuah hutan. Lalu mereka menemukan dua jalan yang berbeda. Satu jalan mengarah ke kebun wortel dan yang satu mengarah ke jurang. Lalu ada seekor Kelinci yang licik menukar tanda jalan tersebut. Pergilah sekelompok kelinci tersebut ke arah jurang, kemudian seekor kelinci licik itu pergi sendiri menuju kebun.

Ternyata kelinci licik itu salah jalan, malah yang ditujunya itu adalah kebun yang penuh dengan ranjau. Akhirnya, dia terjebak dan kesakitan. Ia berteriak meminta tolong kepada kawanannya, tapi tidak ada yang mendengarnya, sedangkan sekawanan kelinci yang lain malah mendapatkan makanan 
yang sangat banyak. Ketika kawanan kelinci sedang menikmati makanannya, mereka tersadar bahwa satu anggota mereka ada yang hilang. Kemudian sekawanan Kelinci itu mencari, dan mendapatkan kelinci yang dicarinya sedang kesakitan. Kemudian, mereka membantu seekor kelinci licik yang terjatuh dan kesakitan. Setelah Kelinci itu ditolong, Kelinci licik tersebut merasa bersalah, kemudian ia meminta maaf, dan mereka semua berbagi makanan dan bermain bersama.

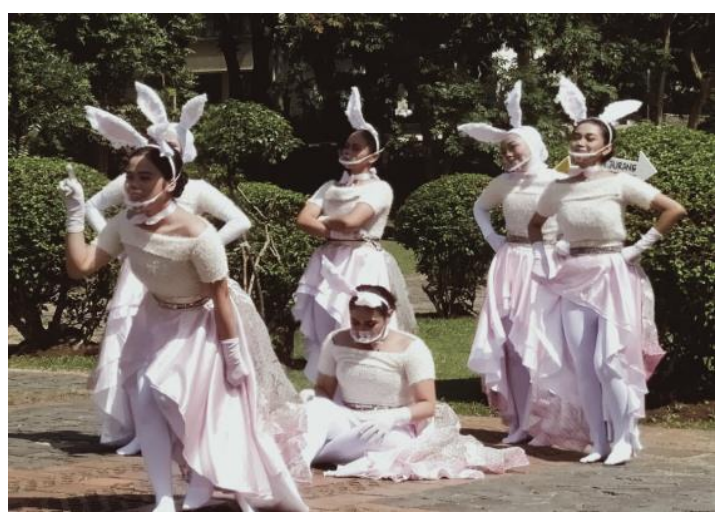

Gambar 3. Tari Kawanan Kelinci

Gerakan tari Kelinci mengimitasikan gerak-gerik Kelinci, dimulai dari melompat, menggerakan kuping, gerakan mencari makan. Musik yang digunakan ialah musik dari lagu kelinci yang tersedia di YouTube ditambah dengan kostum kelinci putih yang membuat karya ini sangatlah menarik. Lokasi pentas di ruang terbuka Taman Baretti Villa Isola, dengan setting pentas Gedung Partere Kampus UPI Bumi Siliwangi.

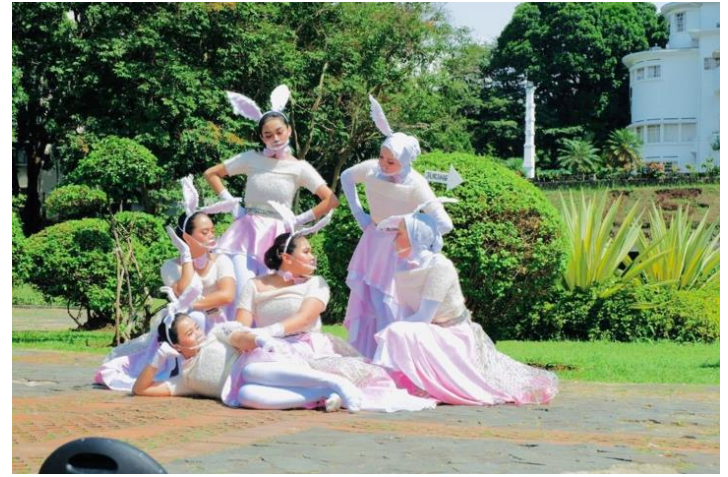

Gambar 4. Kawanan Kelinci Sedang Bermain

\subsection{Kelompok Permainan Anak "Barudak di Buruan"}

Kelompok permainan anak bernama "Barudak di Buruan". Barudak berarti anak-anak, buruan artinya halaman. Pembentukan kelompok ini untuk membawakan karakter kompak. Ketua kelompok adalah Ismail Muladi, S.Pd., dia tidak banyak berpartisipasi dalam proses garap tari karena sakit, tetapi dia mengkoordinasi kelompoknya secara daring. Anggotanya adalah adik-adik mahasiswa Departemen Pendidikan Tari Angkatan 2020. Penari berjumlah 6 orang yaitu Salsa Resti Fauzi; Fannysa Nur Kholifa Rizmawanti; Firli Prihastini; Meilina Susanti; Raisa Fitriah; Ayumitha Nissa Ramdhani. Pembimbing sekaligus penggarap tari adalah Dr. Putri Lilis Dyani, M.Sn.

Permainan anak "Barudak di Buruan" adalah permainan yang biasanya dimainkan secara langsung bersama teman-teman dan bisa juga dilakukan di rumah masing-masing bersama orangtua. Karya ini didalamnya terdapat beberapa permainan anak (kaulinan sunda) yang dikombinasikan dengan gerak tari. Kelompok ini dengan apik menggabungkan beberapa permainan 
secara medley dimulai dari permainan jalan kaki dengan beralaskan batok kelapa, lalu berjalan dengan dua sandal bakiak yang dipakai oleh tiga orang secara bersama, lalu berjalan. Setelah itu, anak-anak bermain Orayorayan, engkle, ucing sumput, cingciripit, sur ser, menganyikan punten mangga. Gambar 5 mengekspresikan permainan sur ser. Permainan ini dilakukan dalam posisi duduk berbaris sambal memegang kaki dan mengusap kaki seraya bernyanyi sur ser. Gambar 6 menggambarkan anak-anak sedang bermain punten mangga artinya permisi dan silahkan.

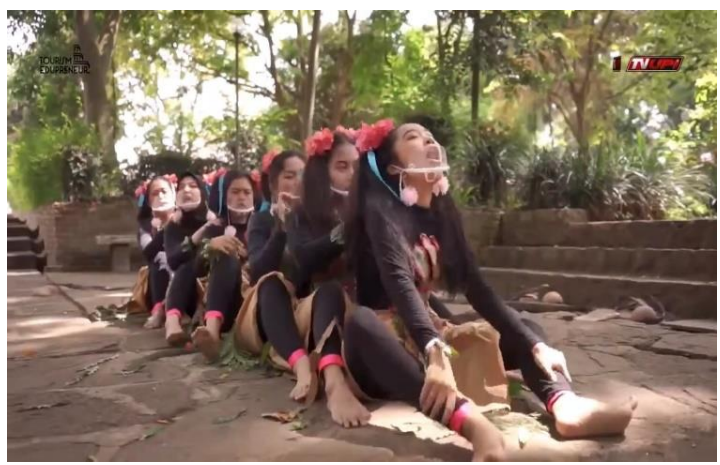

Gambar 5. Permainan Sur ser

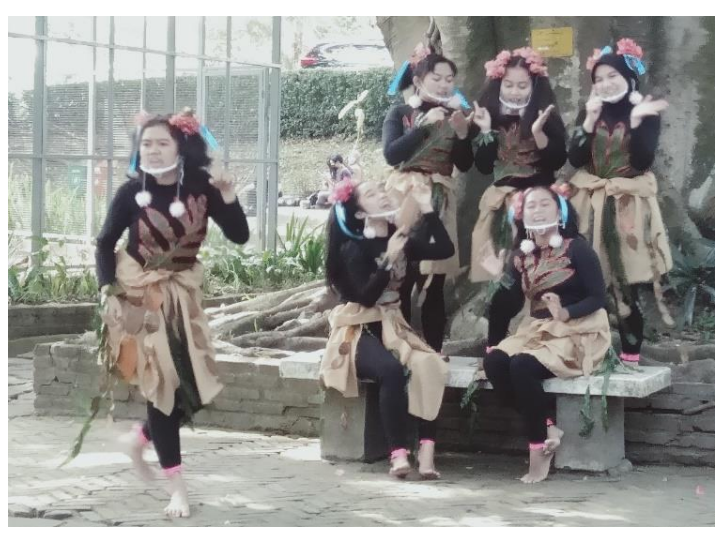

Gambar 6. Permainan Anak "Punten Mangga"

\section{Pembelajaran Tari Anak dan Permainan Anak}

Pembelajaran tari merupakan rangkaian dari produksi karya tari anak dan permainan anak. Pembelajaran tari ini memiliki konsep performing (pertunjukan), learning (belajar seni untuk siswa), dan teaching (dosen mengajar). Tiga tahapan sajian pembelajaran ini merupakan satu kesatuan yang utuh dan saling melengkapi. Pertunjukan seni ditampilkan pada awal, kemudian instruktur mengajak satu penari sebagai peraga gerak untuk diajarkan ke siswa secara virtual agar siswa dapat belajar gerak tari yang ditampilkan. Setelah itu, dosen pembimbing menjelaskan konsep garap tari yang disajikan. Dengan tiga tahapan sajian itu, maka rangkaian itu diberi judul virtual event dan virtual arts learning disingkat Virevale. Melalui Virevale, diharapkan anakanak, keluarga, dan guru sekolah memiliki pengalaman menonton tari dan permainan anak, siswa dapat belajar tari dan permainan anak, serta orangtua dan guru belajar konsep penciptaan tari dan permainan anak. Oleh karena itu, kelompok mahasiswa yang mengembangkan pembelajaran tari disebut kelompok teacher atau instruktur.

Kelompok instruktur tari dipimpin oleh Rumario Patogian, S.Pd. (alumni Departemen Pendidikan Tari UPI). Kelompok ini beranggotakan 6 orang yaitu Mima Afifah Fajria Bawole, Galih Pratama, Ridha Agustiandhy, Wangi Gempita Wijaya, Irwan Saputra, Sofie Wellyamshi Marnis Bongga. Pembimbing pembelajaran tari adalah Juju Masunah, M.Hum., Ph,.D. Untuk pembelajaran Tari Anak dan permainan Anak, yang berperan sebagai instruktur hanya dua orang yaitu Galih Pratama yang menjadi 
instruktur Tari Anak dan Romario Patogian yang menjadi instruktur permainan anak. Dalam mengambil gerak untuk diajarkan kepada anakanak, instruktur ini memilih gerak khas dari tarian yang telah ditampilkan. Pada Gambar 7 menampilkan ciri khas gerak sabilulungan dengan saling berpegangan tangan. Pada gambar 8 memperlihatkan Gerakan khas kelinci yang sedang meloncat. Anak-anak diharapkan mengikuti gerakan yang dicontohkan oleh penari bersama instruktur.

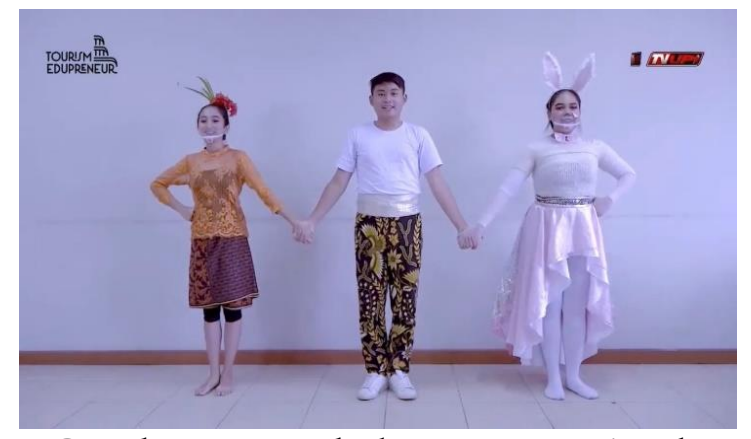

Gambar 7. Pembelajaran Tari Anak "Sabilulungan"

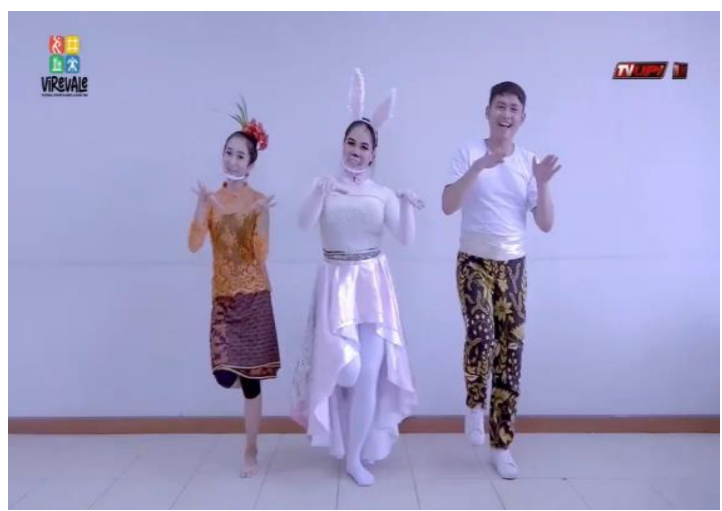

Gambar 8. Pembelajaran Tari

"Kawanan kelinci"

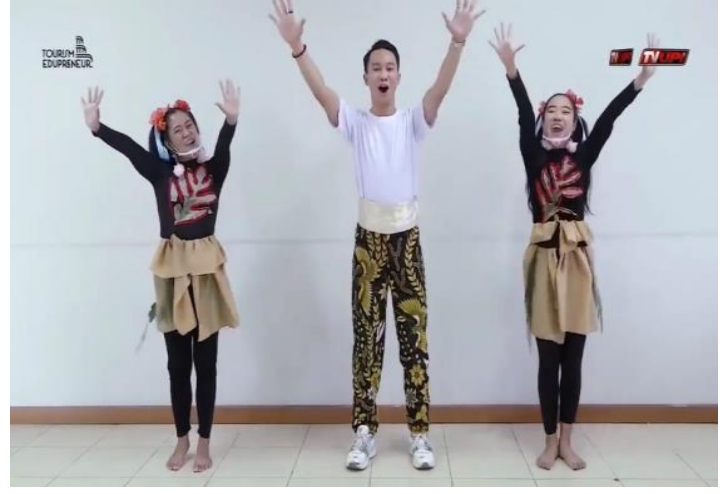

Gambar 9. Pembelajaran Permainan Anak "Barudak di Buruan"

Pada Gambar 9 menggambarkan pembelajaran barudak di buruan dengan gembiranya. Pembelajaran tari "Barudak di Buruan" mengambil salah satu contoh permainan yaitu punten-mangga yang artinya permisisilakan. Instruktur mengajak penonton di rumah untuk mengikuti permainan ini lalu disampaikan pesan moral dibalik permainan yaitu agar anak-anak selalu sopan santun kepada siapapun, orang tua, saudara, maupun teman sebaya.

Yang membedakan pertunjukan seni virtual dengan pertunjukan yang lain ialah terdapat permbelajaran bagaimana cara mempraktikannya (learning to do) bagi para penonton yang ada di rumah. Instruktur Virtual Arts Learning memandu penonton untuk melakukan gerak tari, dan menyampaikan pesan-pesan moral yang terdapat di dalam tarian tersebut. Misalnya, gerak tari "Sabilulungan" adalah berpegangan tangan (Gambar 7), menggambarkan sikap gotong royong, kerjasama dan saling tolong menolong terutama dalam pelestarian lingkungan. Gerak tari kelinci adalah melompat dan meloncat dengan lincah. Lagu pengiring tari Kelinci mengajarkan 
jangan suka berbohong atau kejujuran, pesan moralnya adalah janganlah suka bohong terhadap orang tua, saudara ataupun teman.

Bagian akhir dari pembelajaran ini, instruktur mengundang dosen pembimbing untuk menjelaskan konsep penciptaan tari. Ayo Sunaryo menjelaskan konsep engkle. ENGKLE singkatan dari Entering in Environment (konsep Kembali ke alam dan lingkungan siswa), Navigation (penjelajahan atau pendalaman terhadap elemen dasar), Googling (konsep pencarian gerak berdasarkan eksplorasi dan improvisasi), Knitting and validating (merajut untuk membakukan bagian komposisi hasil eksplorasi dan improvisasi), locking and presenting (kegiatan mengunci dan membakukan komposisi), dan Evaluation (evaluasi kekaryaan setelah pementasan) (Sunaryo, 2020). Konsep ini menggambarkan langkah-langkah penciptaan tari anak oleh orang dewasa. Dalam istilah (Giguere, 2011), tari anak yang dicipta oleh orang dewasa dikelompokkan pada Dance for Children Created by Adults.

Konsep penciptaan tari anak yang digagas oleh Ayo Sunaryo, berbeda dengan yang dikembangkan oleh Dr. Putri Lilis Dyani, M.Sn. dalam karya tari "Barudak di Buruan." Putri Lilis Dyani merujuk pada konsep penciptaan tari anak oleh orang dewasa bersama anak. (Giguere, 2011) menyebutnya Dances for Children created by Adults with Children. Dalam konsep ini, anak-anak berperan aktif dalam mewujudkan tarian. Putri Lilis Dyani menggagas cara penciptaan tari ini dengan metode ngemong artinya mengasuh (Dyani, 2019).

\section{Promosi Tari Anak dan Permainan Anak}

Untuk mempromosikan produksi Tari Anak dan Permainan Anak, terdapat kelompok promosi yang terdiri dari mahasiswa S1 dari Fakultas Pendidikan Ekonomi dan Bisnis (FPEB). Kelompok ini dipimpin oleh Nurulloh Ramdani, sedangkan anggotanya berjumlah 5 orang yaitu Arjun May Sandi, Asti Nurul Alviani, Mesa Amelia, Shalsa Khoiru Nisa, dan Zidane Al Rasyid. Kelompok ini dibimbing oleh dua dosen dari Prodi Managemen dan Prodi Pariwisata, Dr. Maya Sari, S.E. M.M. dan Dr. Vanessa Gaffar SE.Ak, MBA.Kelompok ini melakukan promosi seni dengan menggunakan media social yaitu Instagram, line, WhatsApp, dan email.

\subsection{Promosi melalui Instagram}

Dalam kurun waktu satu bulan, kelompok promosi membuat akun resmi Instagram. Secara berkala, kelompok ini mengunggah foto-foto yang memberitakan kegiatan latihan dan pementasan Virevale. Selain itu, kelompok promosi membuat videovidio trailer yang berisi cuplikan singkat wawancara dengan para pembimbing dan pertunjukan untuk menambah minat apresiator. Akun resmi Instagram adalah @tourismedupreneur_upi. Contoh foto yang diunggah dalam Instagram sebagai berikut. 


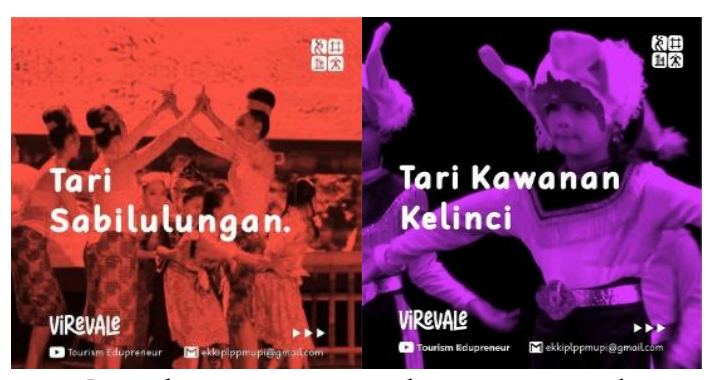

Gambar 10. Bentuk Promosi di Instagram

\subsection{Promosi melalui Whats -App dan Line}

Selain media sosial Instagram, kelompok promosi juga giat menyebarkan info dengan media sosial Chat seperti WhatsApp dan Line. Sasaran yang dikirim info adalah kerabat-kerabat. Kerabat yang dikenal dengan fokus menyebarkan via grup-grup atau tertuju langsung kepada orang tua, teman, dan para penari yang mengikuti kegiatan Virevale.

\subsection{Promosi melalui Email Resmi}

Tim PkM membuat surat undangan resmi ke sekolah-sekolah, khususnya Pendidikan Anak Usia Dini (PAUD) dan Sekolah Dasar (SD). Hal ini mengingat bahwa sasaran penonton adalah anak-anak, orang tua dan guru sekolah. Surat undangan ini, dikirim melalui email oleh kelompok promosi ke beberapa sekolah di daerah Bandung. Isi undangan adalah mengundang untuk menonton Virevale melalui TVUPI Digital. Kelompok promosi mengirimkan kurang lebih 20 sekolah SD dan TK.

\subsection{Pemasaran Seni Secara Virtual}

\subsubsection{Pertunjukan Seni Virtual}

Tujuan utama pertunjukan ialah bukan hanya sekedar membuat pertunjukan virtual saja untuk apresiasi, melainkan untuk memasarkan karya tari atau uji pasar ke sekolah-sekolah, siswa dan guru sebagai stakeholdernya. Seharusnya pertunjukan dilakasanakan secara langsung, akan tetapi karena pandemic covid-19 maka pertunjukan virtual ini merupakan cara uji pasar produksi Tari Anak dan Permainan Anak.

Pemasaran produksi Tari Anak dan Permainan Anak disajikan melalui konsep performing, learning, and teaching atau virtual event and virtual arts learning yang disingkat Virevale. Virevale ini disajikan melalui TV UPI Digital http://tv.upi.edu dan live streaming di Youtube Channel https://www.youtube.com/watch?v $=$ Uxx08X1Uz1c\&feature $=e m b$ title pada tanggal 24 Oktober 2020 jam 9.30. Pengantar sajian diawali oleh rekaman langsung di studio oleh Juju Masunah. Rektor UPI memberi sambutan dan membuka acara Virevale dengan membunyikan angklung secara langsung diikuti rekaman semua tim virevale. Setelah itu, acara dilanjutkan dengan penampilan tari Anak "Sabilulungan" dan "Kawanan Kelinci" secara berturut-turut. Pembelajaran tari oleh instruktur Gilang. Tampilan berikutnya adalah permainan anakanak, pembelajaran tari, dan penjelasan konsep Engkle dan metode ngemong. Setelah tiga tarian, masih ada pertunjukan, pembelajaran, dan 
penjelasan konsep tentang lagu anak dan musik angklung, serta puppet.

Pertunjukan seni virtual ini merupakan sebuah strategi entrepreneurial bricolage yaitu proses membangun jiwa wirausaha bagi para pelaku kreatif. de Klerk (2015), mendiskusikan tentang an entrepreneurial bricolage yaitu sebuah strategi untuk mengkostruksi perilaku dan penampilan aktor-aktor industri kreatif. Konsep bricolage adalah seperti suatu proses gabungan kemampuan kekayaan masyarakat yang sifatnya intelektual dengan sebuah visi baru dari setiap orang untuk melanjutkan kreativitas dan networking. (Simba et al., 2021) merumuskan bricolage sebagai sebuah konsep yang menghubungkan dengan sumber-sumber yang terlihat dan tak terlihat untuk tumbuh dan berkembang. Para pelaku kreatif menggunakan ide, keterampilan, sikap, dan visi mereka untuk bekerjasama secara kolaboratif dalam projek tertentu. Relasi dan kerjasama merupakan proses penting dalam mencipta tujuan-tujuan jangka pendek dan untuk melanjutkan keterampilan berwirausaha dalam sektor industri kreatif. Strategi entrepreneurial bricolage ini digunakan juga dalam membangun kelompok penyelenggara festival yaitu BIPAF Community (Masunah \& Milyartini, 2016).

\subsubsection{Respon Masyarakat}

Setelah sajian seni untuk Anak selesai ditayangkan, maka kami mengagendakan response dari masyarakat dalam bentuk wawancara zoom meeting yang ditayangkan langsung melalui TV UPI. Tim PkM mengundang Prof. Dr. Ida Hamidah, M.Si. sebagai Sekretaris LPPM UPI, Ibu Dra. Irawati Kusumorasri, M.Sn. sebagai pimpinan sanggar tari Candrakirana dari Surakarta, Ibu Ratna Yulianti, M.Pd. sebagai pimpinan sanggar Semesta Tari, serta Saian Badaruddin, M.Pd. Mereka menyampaikan kesan atas tayangan Virevale, dan saran untuk untuk perbaikan penyajian secara virtual di masa depan. Tayangan Virevale ini ditonton oleh lebih 1700 penonton dalam sekali penayangan.

Dengan adanya event ini kami dari tim PkM juga meminta respon dari beberapa apresiator yang telah menonton. Respon tersebut diambil dengan menggunakan angket google form yang diinformasikan kepada penonton setelah acara selesai. Diperoleh 109 responden yang mengisi angket, yaitu sebagai berikut.
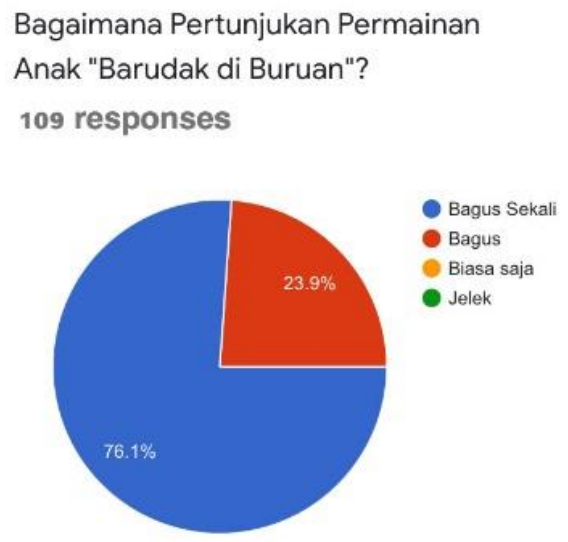

Gambar 11. Respon terhadap tari "Barudak di Buruan" 
Bagaimana Pertunjukan Tari Anak "Tari

Sabilulungan"?

109 responses

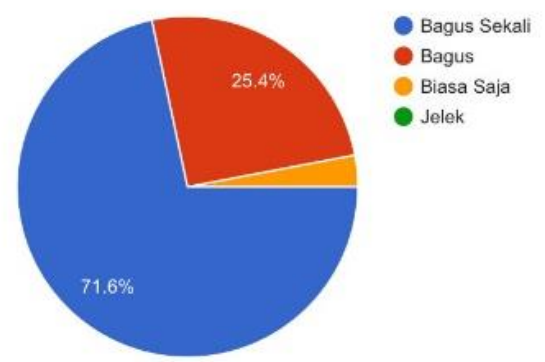

Gambar 12. Response Apresiator terhadap tari "Sabilulungan

Data pada Gambar 11 di atas menunjukan respon apresiator terhadap Tari "Barudak di Buruan" adalah 76,1 \% menyatakan baik sekali dan tidak ada yang menyatakan jelek. Sebanyak $71,6 \%$ responded menyukai sajian tari Sabilulungan dan sajian Virevale, dengan memilih option tarian tersebut sangat baik. Kemudian, kami juga menanyakan minat apresiator atas tampilan Virevale. Pada Gambar 13 menunjukkan jawaban bahwa lebih dari $90 \%$ penonton berminat untuk menonton Kembali virevale.

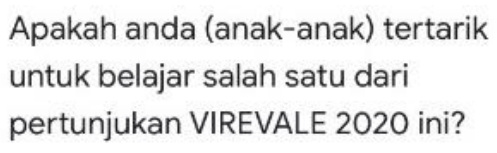

109 responses

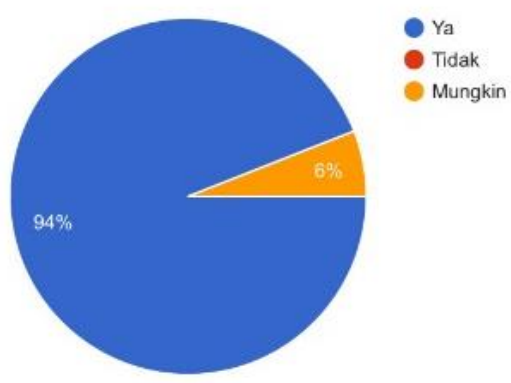

Gambar 13. Response Apresiator terhadap Virevale 2020
Beberapa apresiator pun ada yang mengunggah foto ketika sedang menonton acara pertujukan di TV UPI ini, dengan men-tagging akun official Instagram Tourism Edupreneur, tim promosi pun dapat membagikan ulang kepada apresiator lainnya. Sajian Virevale melalui TVUPI Digital ini merupakan langkah yang tepat di Era pandemic covid-19 ini. Kehadiran penonton secara virtual berkat upaya dari kelompok promosi seni, sedangkan uji pasar dibantu oleh Tim dokumentasi dan tim penayangan TV UPI Digital. Namun demikian, usaha seni belum dapat dilihat langsung keuntungan secara ekonomi, dibandingkan dengan mahasiswa yang dibina oleh (Jaharuddin et al., 2019) yang mengembangkan usaha makanan atau kuliner. Namun Demikian, nilai-nilai kewirausahaan seperti diungkapkan oleh (Sukirman, 2017) seperti kreativitas dan inovasi dalam kegiatan Virevale telah memotivasi perilaku wirausaha mahasiswa. Menurut (Utama et al., 2020) terdapat korelasi antara motivasi wirausaha dengan minat wirausaha. Semakin baik motivasi wirausaha semakin meningkat minat wirausaha. Hal inilah yang diharapkan dalam kegiatan Virevale ini. Meskipun secara ekonomi belum menghasilkan tetapi motivasi dan minat wirausaha mahasiswa terlah tumbuh.

\section{KESIMPULAN}

Melalui rangkaian kegiatan yang intensif $\mathrm{PkM}$ ini berhasil membina 34 mahasiswa yang dibagi ke dalam lima kelompok mahasiswa yaitu tiga kelompok yang memproduksi karya 
tari anak dan permainan anak. Satu kelompok yang mengembangkan pembelajarannya, dan satu kelompok yang mendukung dalam promosi karya tari. Kelima kelompok ini saling bekerjasama untuk memproduksi karya seni, mengembangkan pembelajaran, mempromosikan melalui media social, dan menyajikan produk dalam bentuk virtual event dan virtual arts learning disingkat Virevale.

Konsep penyajian Virevale dimulai dari penyajian karya atau performing, pembelajaran tentang karya yang disajikan untuk anak-anak atau learning, dan penyajian konsep produksi bagi guru dan orangtua atau teaching. Ketiga tahapan ini merupakan model penyajian yang dikemas secara virtual melalui TV UPI Digital. Mahasiswa yang tergabung dalam kegiatan ini memiliki semangat dan motivasi yang tinggi untuk melanjutkan berwirausaha jasa kreatif sub sector pertunjukan (penari) dan instruktur/pelatih tari anak. Mereka menawarkan kepada anak-anak atau masyarakat untuk belajar langsung di UPI atau melatih tari anak ke sekolahsekolah.

Cara performing-learning-teaching merupakan model pembinaan wirausahan jasa kreatif seni pertunjukan. Para apresiator, baik guru maupun anak-anak diharapkan lebih mengenal, menikmati sekaligus belajar dari pertunjukan-pertunjukan yang ditampilkan. Kegiatan ini perlu ditindaklanjuti untuk memperkuat kelompok mahasiswa berwirausaha yang dikaitkan dengan program Tourism Edupreneur yang sedang dikembangkan oleh Universitas Pendidikan Indonesia.

\section{DAFTAR PUSTAKA}

de Klerk, S. (2015). The creative industries: An entrepreneurial bricolage perspective. Management Decision, 53(4), 828842.

https://doi.org/10.1108/MD-032014-0169

Dyani, P. L. (2019). Creating Dances with Children based on Traditional Games. International Conference on Arts and Design Education (ICADE) 2019.

Giguere, M. (2011). Dances for Children, With Children, and by Children: looking at Recital Dance through a lens of Childre's Culture. Journal of Dance Education, 11(3), 84-89.

Jaharuddin, J., Purnawan, I., Mujiastuti, R., Muthmainnah, R. N., \& Prasetyawati, M. (2019). Strategi Melahirkan Mahasiswa Pengusaha Pemula (Studi Kasus Mahasiswa Universitas Muhammadiyah Jakarta). Jurnal Kewirausahaan Dan Bisnis, 24(13), 25.

https://doi.org/10.20961/jkb.v2 4i13.29310

Karyaningsih, D. R. P. (2017). Hubungan Kreativitas, Efikasi Diri dan Intensi Berwirausaha pada Mahasiswa. Jurnal Pendidikan Ekonomi Dan Bisnis (JPEB), 5(2), 162-175. https://doi.org/10.21009/jpeb.00 5.2 .4

Masunah, J. (2019a). Pendampingan 
Wirausaha Seni Pertunjukan Bagi

Mahasiswa UPI melalui

ProduksiWayang \& Tari Kreasi untuk Pendidikan.

Masunah, J. (2019b). Peran perguruan tinggi dalam mengembangkan industri kreatif sub sektor seni pertunjukan di Indonesia. In F. A. Hamied \& K. Komalasari (Eds.), Ilmu Pendidikan, Pendidikan Bahasa dan Seni di Era Revolusi Industri 4.0 (pp. 352-378). UPI Press.

Masunah, J., \& Milyartini, R. (2016). Building Entrepreneurship in Performing Arts Industry through the Incubation Model. 15, 838-843.

Pangestu. (2014). Klasifikasi Baku Lapangan Usaha Indonesia (KBLI) Bidang Ekonomi Kreatif.

Pangestu, M. E. (2014). Ekonomi Kreatif: Kekuatan Baru Indonesia menuju 2025. Kementerian Pariwisata dan Ekonomi Kreatif.

Simba, A., Ojong, N., \& Kuk, G. (2021). Bricolage and MSEs in emerging economies. International Journal of Entrepreneurship and Innovation, 22(2), 112-123. https:// doi.org/10.1177/1465750 320969621

Stoecker, R. (2005). Research Methods for Community Change. Sage Publication.

Sukirman, S. (2017). Jiwa Kewirausahaan dan Nilai Kewirausahaan Meningkatkan Kemandirian Usaha melalui Perilaku Kewirausahaan. Jurnal Ekonomi Dan Bisnis, 20(1), 117. https:// doi.org/10.24914/jeb.v20 i1.318

Sumarsono, H. (2013). Faktor-Faktor yang Mempengaruhi Intensi Wirausaha Mahasiswa Universitas Muhamadiyah Ponorogo. Jurnal Ekuiibrium, 1(2), 62-88.

Sunaryo, A. (2020). Dasar-Dasar Koreografi. UPI Press.

Utama, D. H., Mulyadi, H., Imbragia, \& Disman, D. (2020). Pengaruh Pembelajaran Kewirausahaan dan Motivasi Wirausaha terhadap Niat Berwirausaha. Journal of Business Management Education (JBME), 5(2), 16-21. 